\title{
ARBORIZAÇÃO VIÁRIA DE LAVRAS - MG: FLORÍSTICA E USO DE ESPÉCIES NATIVAS
}

\author{
STREET TREES OF LAVRAS - MG: FLORISTIC AND USE OF NATIVE SPECIES
}

\begin{abstract}
Gabriel de Assis Pereira ${ }^{1}$, Ana Carolina Maioli Campos Barbosa ${ }^{2}$, Altamir Fernandes Oliveira ${ }^{3}$, Elisa Mousinho Gomes Carvalho Silva ${ }^{4}$, Patrícia Vieira Pompeu ${ }^{5}$, Monik Begname de Castro ${ }^{6}$
\end{abstract}

\section{RESUMO}

As florestas urbanas são essenciais para a manutenção da qualidade de vida nas cidades e desempenham um importante papel para a conservação da flora. Assim, o objetivo desse trabalho foi realizar o inventário parcial da arborização viária da cidade de Lavras - MG, com o levantamento de sua composição florística e a averiguação do uso de espécies nativas. Para isso, foram percorridos $43,34 \mathrm{~km}$ de vias públicas da cidade, distribuídas em 10 bairros. Foram catalogados 415 indivíduos arbóreoarbustivos, distribuídos em 43 espécies, 39 gêneros e 26 famílias botânicas. As espécies com as maiores frequências relativas foram a Murraya paniculata (L.) Jack. (20,0\%), Poincianella pluviosa (DC.) L.P.Queiroz (15,7\%) e Lagerstroemia indica L. (12,5\%). Foi constatado que 37,8\% dos indivíduos são de espécies de comportamento arbustivo. Os indivíduos foram classificados em 19 espécies nativas, dessas sete são autóctones. Conclui-se que é necessário a melhoria do planejamento da arborização viária, priorizando o uso de espécies adequadas e preferencialmente autóctones da região. As informações geradas por essa pesquisa poderão auxiliar o poder público nas diretrizes e ações necessárias para a melhoria da arborização da cidade de Lavras - MG.

Palavras-chave: Biodiversidade; Cerrado; Floresta Urbana; Inventário; Planejamento Urbano.

\section{ABSTRACT}

Urban forests are essential for maintaining the quality of life in cities and play an important role in the conservation of flora. Thus, the aim of this study was to realize a partial inventory of urban trees in the city of Lavras - MG, with the survey of its floristic composition and the investigation of the use of native species. For that were covered $43.34 \mathrm{~km}$ of public roads in the city, distributed in 10 neighborhoods. A total of 415 trees and shrubs individuals were cataloged belonging to 43 species, 39 genera and 26 botanical families. The species with the highest relative frequency were Murraya paniculata (L.) Jack. (20.0\%) Poincianella pluviosa (DC.) LPQueiroz (15.7\%) and Lagerstroemia indica L. (12.5\%). It was found that $37.8 \%$ of individuals are species of shrub behavior. The individuals were classified in 19 native species, these seven are indigenous forest remnants of Lavras - MG. It is concluded that it is necessary to improve the planning of urban forestry, prioritizing the use of appropriate species and preferably native of the region. The information generated by this research may help the government in the guidelines and actions necessary to improve the afforestation of the city of Lavras - MG.

Keywords: Biodiversity; Cerrado; Inventory; Urban forest; Urban planning.

Recebido em 25.08.2020 e aceito em 02.03.2020

1 Engenheiro Florestal. Doutor. Universidade Federal de Lavras. Lavras/MG. Email: gabriel_assispereira@hotmail.com

2 Engenheira Florestal. Doutora. Professora Adjunta da Universidade Federal de Lavras. Lavras/MG. Email: anabarbosa@ufla.br

3 Biólogo e Administrador Público. Doutor. Professor Adjunto da Universidade Federal dos Vales do Jequitinhonha e Mucuri. Diamantina/MG. Email: altamirf83@gmail.com

4 Engenheira Florestal. Mestra. Universidade Federal de Lavras. Lavras/MG. Email: elisa.mousinho@gmail.com

5 Engenheira Florestal. Doutora. Professora Adjunta da Universidade Estadual do Mato Grosso do Sul. Aquidauana/MS. Email: patpompeu@hotmail.com

6 Engenheira Florestal. Mestra. Professora Substituta da Universidade Estadual do Mato Grosso do Sul. Aquidauana/MS. Email: monikbegname@gmail.com 


\section{INTRODUÇÃO}

Os serviços ambientais, desempenhados pelas florestas urbanas, são reconhecidamente importantes para a manutenção da qualidade de vida nas cidades (GÓMEZBAGGETHUM; BARTON, 2013; MELO; DIAS, 2019). Com o aumento das áreas urbanizadas, o planejamento voltado para o manejo das áreas verdes e arborização viária, partes constituintes das florestas urbanas, se faz necessário (MELO; DIAS, 2019, OLIVEIRA et al., 2015).

No manejo das florestas urbanas, a diversidade de espécies é um ponto que deve ser abordado, uma vez que a diversificação das espécies na comunidade vegetacional proverá uma maior proteção contra a disseminação de doenças e pragas, em comparação com povoamentos arbóreos dominados por poucas espécies (ALMAS; CONWAY, 2016; SANTAMOUR, 1990) e em relação às alterações ambientais causadas pelas mudanças climáticas, determinadas espécies vegetais podem ser mais vulneráveis a essas alterações (ROLOFF; KORN; GILLNER, 2009; NOWAK et al., 2013).

Para a manutenção da diversidade nos plantios urbanos, recomendações acerca da frequência relativa máxima dos táxons (espécies, gêneros e famílias) são discutidas na literatura. Uma regra comumente adotada é de se utilizar no máximo 10\% dos indivíduos em uma única espécie, $20 \%$ em um gênero e 30\% para família, conforme valores propostos por Santamour (1990).

Outro ponto a ser considerado na gestão de florestas urbanas é a priorização do uso de espécies nativas, pois contribui para a conservação da flora, promove o paisagismo coerente com a vegetação regional, além das espécies nativas serem mais rústicas ao clima local e podem ser uma oportunidade para as práticas de educação ambiental, onde a população pode fazer o reconhecimento das espécies nativas inseridas na mancha urbana (CASTRO; MORO; ROCHA, 2011; CUPERTINO; EISELOHR, 2013; ALMAS; CONWAY, 2016; OSAKA; TAKENAKA; SILVA, 2016). Porém, o que se observa em várias cidades brasileiras é a predominância de espécies exóticas (ALMEIDA; RONDON NETO, 2010) e uma possível justificativa para essa situação está na falta de informações sobre a flora brasileira e o potencial paisagístico de suas espécies (LORENZI, 2002).

Para o conhecimento do acervo arbóreo de determinada cidade, visando delinear o planejamento da sua floresta urbana, se faz necessário o levantamento quali-quantitativo de seus componentes. Assim, o objetivo desse trabalho foi realizar o inventário parcial da arborização viária da cidade de Lavras - MG, a fim de obter informações de sua composição florística e averiguar o uso de espécies nativas. 


\section{MATERIAL E MÉTODOS}

O município de Lavras localiza-se na região Sul do estado de Minas Gerais, sob as coordenadas $21^{\circ} 14^{\prime} 30^{\prime \prime}$ Sul e $45^{\circ}$ 00' 00" Oeste, com uma altitude média de 919 metros (Figura 1). Dados indicam que sua população estimada é de 101.208 habitantes, sendo que 95,3\% residem no meio urbano (INSTITUTO BRASILEIRO DE GEOGRAFIA E ESTATÍSTICA, 2018) e segundo informações da Prefeitura Municipal de Lavras, a cidade é composta por 110 bairros urbanos.

O município de Lavras - MG está em uma região ecotonal dos domínios Cerrado e Mata Atlântica, onde são encontrados remanescentes de Floresta Estacional Semidecidual, Campo, Campo Rupestre e Cerrado (SOUZA et al., 2003; DALANESI; OLIVEIRA-FILHO; FONTES, 2004; PEREIRA et al., 2010). O clima da região é do tipo Cwa (clima tropical de altitude), segundo a classificação de Köppen, com médias anuais de precipitação e temperatura de $1.493 \mathrm{~mm}$ e $19,3^{\circ} \mathrm{C}$ respectivamente (VILELA; RAMALHO, 1979).

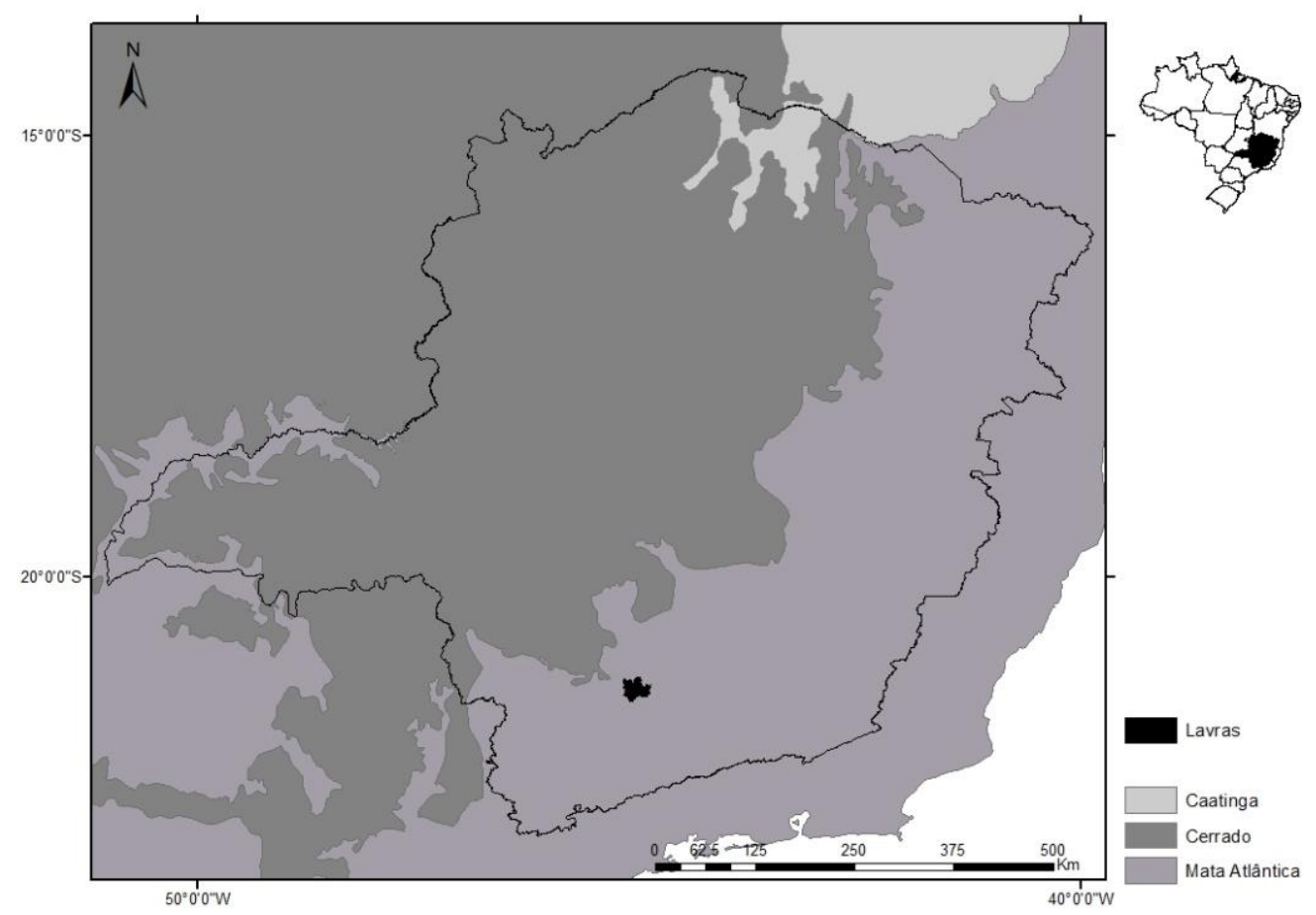

Figura 1. Localização do município de Lavras - MG, com a representação dos domínios fitogeográficos Figure 1. Location of the municipality of Lavras - MG, with representation of the phytogeographic domains

Para o levantamento da arborização viária foi realizado um inventário parcial, onde os indivíduos arbóreo-arbustivos de 10 bairros urbanos foram inventariados, o que representa 9,1\% dos bairros urbanos de Lavras-MG e esses foram determinados por sorteio. Posteriormente, foi calculado o comprimento da rede viária pública de cada bairro selecionado, 
com o auxílio da ferramenta "Path" do programa Google Earth Pro, a qual mede o comprimento de um segmento com múltiplos pontos.

Foram catalogados todos os indivíduos arbóreo-arbustivos presentes nas calçadas e canteiros centrais, que apresentavam altura mínima de 2,5 metros. Foi adotada essa altura de referência para avaliar apenas os indivíduos, que apresentavam o padrão mínimo de qualidade de mudas destinadas ao meio urbano (OLIVEIRA et al., 2015). Além disso, foi mensurada a largura da calçada ou canteiro central, onde estavam inseridos os indivíduos arbóreoarbustivos.

Com a obtenção do número total dos indivíduos arbóreo-arbustivos e do comprimento total das vias públicas inventariadas foi calculado o número de árvores por quilômetro de via (Árvore. $\mathrm{km}^{-1}$ ), conforme metodologia apresentada por Almeida e Rodon Neto (2010).

Dados sobre a origem das espécies catalogadas foram consultados em bibliografias específicas (LISTA DE ESPÉCIES DA FLORA DO BRASIL, 2012; OLIVEIRA FILHO, 2010; LORENZI et al. 2003; LORENZI, 2002), determinando se as espécies eram exóticas ou nativas do Brasil. Para as espécies tidas como nativas, também foram determinados os domínios fitogeográficos brasileiros de sua ocorrência natural. E para determinar se a espécie era autóctone da região de Lavras-MG foram consultados levantamentos florísticos de remanescentes vegetacionais do município (SOUZA et al., 2003; DALANESI; OLIVEIRAFILHO; FONTES, 2004; PEREIRA et al., 2010).

Para a estratificação das espécies em altura potencial, seguimos a metodologia descrita por Oliveira et al. (2015), classificando as espécies em pequeno porte (menor ou igual a $6 \mathrm{~m}$ ), médio porte (entre 6 e $10 \mathrm{~m}$ ) e grande porte (maior que 10m).

Foram determinadas as frequências relativas de cada espécie, gênero e família por meio da fórmula:

$$
F R=\left(\frac{n i}{n t}\right) * 100
$$

Sendo: FR = Frequência relativa; $\mathrm{ni}=$ Número de indivíduos da espécie, gênero ou família; nt = Número total de indivíduos

A cobertura de copa $\left(\mathrm{m}^{2}\right)$ para cada espécie foi determinada pelo somatório das áreas de copa de cada indivíduo. A área de copa individual foi obtida através da área do círculo, o raio utilizado foi calculado através da média aritmética de quatro raios, obtidos em campo, para cada indivíduo. 


\section{RESULTADOS E DISCUSSÃO}

Os dez bairros selecionados para inventário da arborização viária de Lavras - MG são apresentados na tabela 1 , bem como o comprimento total de suas vias públicas.

Tabela 1. Relação dos dez bairros urbanos de Lavras - MG selecionados para o inventário da arborização viária, com o respectivo comprimento das vias públicas

Table 1. List of the ten urban neighborhoods of Lavras - MG selected for the inventory of street trees, with its respective length of public roads.

\begin{tabular}{lc}
\hline Bairro & Comprimento das vias públicas $(\mathbf{m})$ \\
\hline Água Limpa & 3965 \\
Centenário & 3107 \\
Centro & 9941 \\
Jardim Eldorado & 3570 \\
Jardim Fabiana & 3590 \\
João da Cruz Botrel & 3631 \\
Nova Lavras & 3920 \\
Retiro & 3876 \\
Vila Paraíso & 3403 \\
Vila São Francisco & 4336 \\
\hline Total & $\mathbf{4 3 3 3 9}$ \\
\hline
\end{tabular}

A composição florística da arborização viária dos bairros inventariados de Lavras - MG é apresentada na Tabela 2. Foram catalogados 415 indivíduos arbóreo-arbustivos, distribuídos em 43 espécies, 39 gêneros e 26 famílias botânicas. Com relação ao hábito, 61,2\% dos indivíduos foram classificados como árvores, 37,8\% em arbustos e 1,0\% em palmeiras.

As espécies com maior frequência relativa (FR\%) foram a Murraya paniculata (L.) Jack. (20,0\%), Poincianella pluviosa (DC.) L.P.Queiroz (15,7\%), Lagerstroemia indica L. $(12,5 \%)$ e Tibouchina granulosa (Desr.) Cogn. (8,2\%), segundo Lorenzi (2002) e Lorenzi et al. (2013) essas espécies são amplamente utilizadas na arborização das cidades das regiões Sul e Sudeste do Brasil.

Tabela 2. Composição florística da arborização viária da cidade de Lavras - MG.

Table 2. Floristic composition of street trees in the city of Lavras - MG.

\begin{tabular}{lcclllll}
\hline Espécie & Nome Comum & Família & O C M P & FA FR \\
\hline Murraya paniculata (L.) Jack. & Murta & Rutaceae & E & P & 83 & 20,0 \\
Poincianella pluviosa (DC.) L.P.Queiroz & Sibipiruna & Fabaceae & N X X & G & 65 & 15,7 \\
Lagerstroemia indica L. & Resedá & Lythraceae & E & P & 52 & 12,5 \\
Tibouchina granulosa (Desr.) Cogn. ${ }^{*}$ & Quaresmeira & Melastomatacae & N & X & G & 34 & 8,2 \\
Schinus molle L. & Chorão & Anacardiaceae & N & X & M & 33 & 8,0 \\
Tecoma stans (L.) Juss. ex Kunth & Falso-ipê & Bignoniaceae & E & M & 18 & 4,3 \\
Ficus benjamina L. & Figueira & Moraceae & E & G & 15 & 3,6 \\
Thuja occidentalis L. & Tuia & Cupressaceae & E & G & 12 & 2,9
\end{tabular}




\begin{tabular}{|c|c|c|c|c|c|c|c|}
\hline Espécie & Nome Comum & Família & $\mathrm{OC}$ & $M$ & $\mathbf{P} \mathbf{F}$ & FA & FR \\
\hline Hibiscus rosa-sinensis L. & Hibisco & Malvaceae & $\mathrm{E}$ & & $P$ & 9 & $\overline{2,2}$ \\
\hline $\begin{array}{l}\text { Handroanthus impetiginosus (Mart. ex } \\
\text { DC.) Mattos* }\end{array}$ & Ipê-roxo & Bignoniaceae & $\mathrm{NX}$ & $x$ & G & 7 & 1,7 \\
\hline $\begin{array}{l}\text { Callistemon viminalis (Sol. ex Gaertn.) } \\
\text { G.Don }\end{array}$ & Escova-de-garrafa & Myrtaceae & E & & M & 6 & 1,4 \\
\hline Eugenia uniflora $L$. & Pitangueira & Myrtaceae & $N X$ & $x$ & M & 6 & 1,4 \\
\hline $\begin{array}{l}\text { Handroanthus chrysotrichus (Mart. ex } \\
\text { DC.) Mattos }{ }^{*}\end{array}$ & Ipê-tabaco & Bignoniaceae & $N X$ & $x$ & M & 6 & 1,4 \\
\hline $\begin{array}{l}\text { Handroanthus serratifolius (A.H.Gentry) } \\
\text { S.Grose* }\end{array}$ & Ipê-amarelo & Bignoniaceae & $N X$ & $x$ & $\mathrm{G}$ & 6 & 1,4 \\
\hline Tabebuia roseoalba (Ridl.) Sandwith & Ipê-branco & Bignoniaceae & $N X$ & $x$ & G & 6 & 1,4 \\
\hline Michelia champaca L. & Magnólia & Magnoliaceae & E & & M & 5 & 1,2 \\
\hline Brunfelsia uniflora (Pohl) D.Don & Manacá-de-jardim & Solanaceae & $N X$ & $x$ & $\mathrm{P}$ & 4 & 1,0 \\
\hline Leucaena leucocephala (Lam.) de Wit & Leucena & Fabaceae & $\mathrm{E}$ & & M & 4 & 1,0 \\
\hline Licania tomentosa (Benth.) Fritsch & Oiti & Chrysobalanaceae & $N X$ & $x$ & $\mathrm{G}$ & 4 & 1,0 \\
\hline Psidium guajava L. & Goiabeira & Myrtaceae & $\mathrm{E}$ & & M & 4 & 1,0 \\
\hline Ceiba speciosa (A.St.-Hil.) Ravenna & Paineira & Malvaceae & $N \times$ & $x$ & $G$ & 3 & 0,7 \\
\hline $\begin{array}{l}\text { Dypsis lutescens (H.Wendl.) Beentje; } \\
\text { J.Dransf. }\end{array}$ & Areca-bambu & Arecaceae & $\mathrm{E}$ & & M & 3 & 0,7 \\
\hline Terminalia catappa L. & Sete-copas & Combretaceae & $E$ & & G & 3 & 0,7 \\
\hline Araucaria heterophylla (Salisb.) Franco & Pinheiro-de-norfolk & Araucariaceae & $E$ & & G & 2 & 0,5 \\
\hline $\begin{array}{l}\text { Codiaeum variegatum (L.) Rumph. ex } \\
\text { A.Juss. }\end{array}$ & Cróton & Euphorbiaceae & $E$ & & $P$ & 2 & 0,5 \\
\hline Duranta erecta L. & Pingo-de-ouro & Verbenaceae & $N X$ & $x$ & $\mathrm{P}$ & 2 & 0,5 \\
\hline Handroanthus heptaphyllus (Vell.) Mattos & Ipê-rosa & Bignoniaceae & $N \times$ & & $\mathrm{G}$ & 2 & 0,5 \\
\hline Machaerium villosum Vogel $^{\star}$ & Jacarandá-paulista & Fabaceae & $N X$ & $x$ & G & 2 & 0,5 \\
\hline Nerium oleander $\mathrm{L}$. & Espirradeira & Apocynaceae & E & & $\mathrm{P}$ & 2 & 0,5 \\
\hline Punica granatum L. & Romanzeira & Lythraceae & $E$ & & $P$ & 2 & 0,5 \\
\hline Anadenanthera colubrina (Vell.) Brenan* & Angico-branco & Fabac & $N \times$ & & $\mathrm{G}$ & 1 & 0,2 \\
\hline Bauhinia forficata Link & Pata-de-vaca & Fabaceae & $\mathrm{N}$ & $x$ & $\mathrm{G}$ & 1 & 0,2 \\
\hline Bauhinia variegata $\mathrm{L}$. & Unha-de-vaca & Fabaceae & $E$ & & $M$ & 1 & 0,2 \\
\hline Beaucarnea recurvata Lem. & Pata-de-elefante & Asparagaceae & $E$ & & $\mathrm{P}$ & 1 & 0,2 \\
\hline Bougainvillea glabra Choisy & Primavera & Nyctaginaceae & $\mathrm{N}$ & $\mathrm{x}$ & $\mathrm{G}$ & 1 & 0,2 \\
\hline Camellia japonica L. & Camélia & Theaceae & $E$ & & $P$ & 1 & 0,2 \\
\hline Eriobotrya japonica (Thunb.) Lindl. & Nespereira & Rosaceae & $E$ & & G & 1 & 0,2 \\
\hline Mangifera indica L. & Mangueira & Anacardiaceae & $E$ & & G & 1 & 0,2 \\
\hline Melia azedarach L. & Santa-bárbara & Meliaceae & $E$ & & G & 1 & 0,2 \\
\hline Schefflera arboricola (Hayata) Merr. & Cheflera & Araliaceae & E & & $P$ & 1 & 0,2 \\
\hline Spathodea campanulata P.Beauv. & Espatódea & Bignoniaceae & $E$ & & G & 1 & 0,2 \\
\hline $\begin{array}{l}\text { Syagrus romanzoffiana (Cham.) } \\
\text { Glassman* }\end{array}$ & Jerivá & Arecaceae & $N \times$ & $x$ & G & 1 & 0,2 \\
\hline Triplaris americana $\mathrm{L}$. & Formigueiro & Polygonaceae & $N \times$ & $x$ & G & 1 & 0,2 \\
\hline Total & & & & & \multicolumn{2}{|c|}{415} & 100 \\
\hline
\end{tabular}

LEGENDA: $\mathrm{O}$ = Origem (E-espécie exótica / N-espécie nativa); $\mathrm{C}=$ espécie nativa brasileira de ocorrência natural no domínio fitogeográfico do Cerrado; $M A$ = espécie nativa brasileira de ocorrência natural no domínio fitogeográfico da Mata Altântica; * Espécie autóctone; $P$ = Porte (P-pequena: até 6 m / M-média: de 6 a 10 m / G-grande: maior que $10 \mathrm{~m}), \mathrm{FA}=$ Frequência Absoluta e FR = Frequência Relativa em \%.

Pode-se observar que metade dos indivíduos está concentrada em apenas quatro espécies. O gênero Murraya foi o mais comum, o qual representou $20 \%$ da população total. As 
famílias rutaceae e fabaceae foram as mais representativas, com 20,0\% e 17,8\% dos indivíduos respectivamente. Na Figura 2, é apresentada a frequência relativa das famílias botânicas sobre a população total da arborização viária

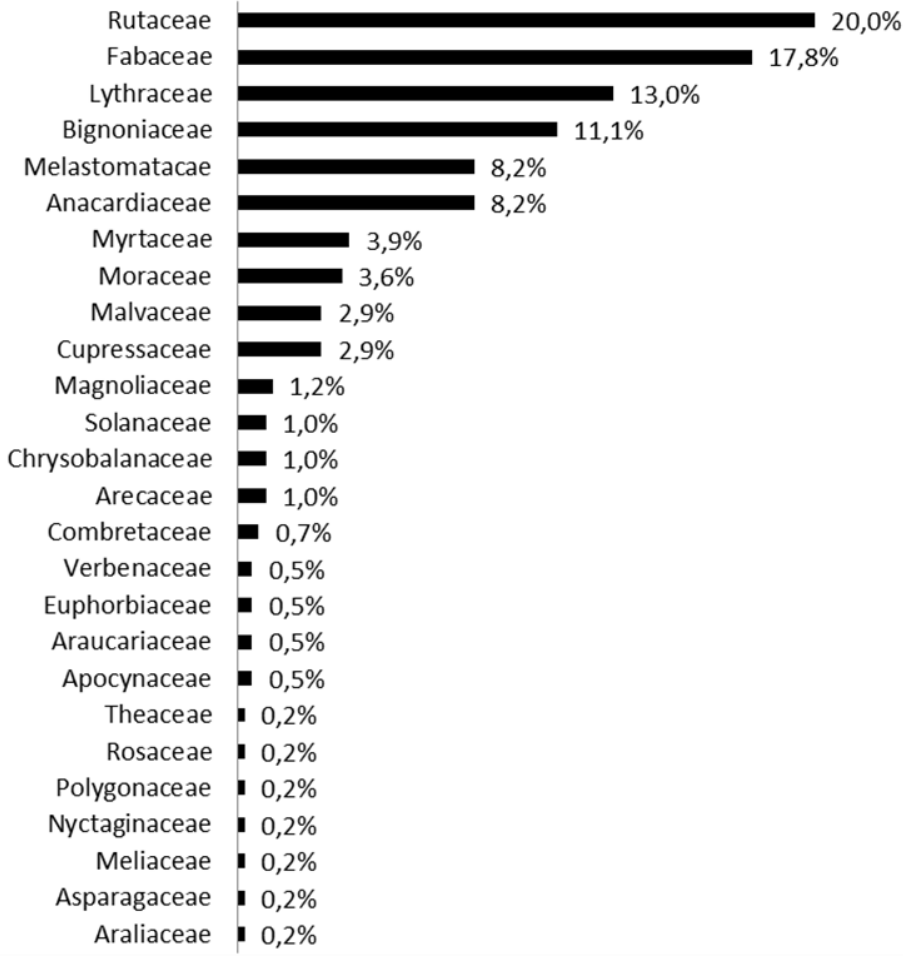

Figura 2. Frequência relativa das famílias botânicas catalogadas no inventário da arborização viária de Lavras - MG

Figure 2. Relative frequency of cataloged botanical families in the inventory of street trees of Lavras - MG

A concentração dos indivíduos em poucas espécies é um fenômeno comum nas cidades brasileiras (ALMEIDA; RONDON NETO, 2010; LUNDGREN; SILVA; ALMEIDA, 2013). $\mathrm{Na}$ literatura são encontradas recomendações de valores referenciais para manterem o mínimo desejável de diversidade na arborização das cidades, dentre essas recomendações está a regra do 10/20/30 (SANTAMOUR, 1990), que significa utilizar no máximo 10\% dos indivíduos em uma única espécie, 20\% em um gênero e 30\% para família. Esses valores foram definidos por estudos realizados em áreas urbanas nos Estados Unidos, e que tiveram como objetivo a redução da disseminação de doenças e pragas nas árvores presentes na arborização urbana. Como exemplo a doença "Dutch elm." causada pelo fungo Ophiostoma ulmi (Buisman) Nannf., que devastou a arborização viária de cidades americanas com baixa riqueza de espécies (SANTAMOUR, 1990).

Na arborização viária de Lavras - MG, as três espécies mais frequentes ultrapassaram o valor recomendado. Ao nível de gênero e família, a frequência do táxon mais comum ficou abaixo do valor de referência máximo, 20 e 30\% respectivamente. Diante do exposto, é 
necessária a diversificação da arborização viária de Lavras - MG, devendo-se evitar a concentração de indivíduos em poucas espécies.

A Figura 3 apresenta a área de copa média $\left(\mathrm{m}^{2}\right)$, cobertura de copa $\left(\mathrm{m}^{2}\right)$ e a tendência da frequência relativa (FR\%) para as dez espécies mais abundantes. A cobertura de copa de todas os indivíduos inventariados foi de $7431,09 \mathrm{~m}^{2}$ e observamos que as espécies Poincianella pluviosa, Handroanthus impetiginosus e Schinus molle apresentaram as maiores áreas de copa média entre os indivíduos, com 45,2, 29,9 e 17,3 m², respectivamente. A espécie Poincianella pluviosa aliada ao fato de ter a segunda maior frequência relativa da comunidade arbóreaarbustiva, obteve a maior cobertura de copa com $2939,2 \mathrm{~m}^{2}$, o que representa $39,6 \%$ da cobertura de copa total. Já a espécie Murraya paniculata mesmo tendo a maior frequência relativa da comunidade arbórea-arbustiva (20\%), seu valor de cobertura de copa foi de apenas $505,9 \mathrm{~m}^{2}$ (7\% da cobertura de copa total), isso é devido ao seu hábito arbustivo com pequena área de copa.

Em estudos de percepção com os moradores das cidades, o serviço ambiental mais lembrado pela presença de árvores no sistema urbano é o fornecimento de sombra (RODRIGUES et al., 2010) e a espécie Poincianella pluviosa devido a sua copa ornamental e de crescimento médio a rápido, se tornou uma das principais espécies para implantação nas cidades na região centro-sul do Brasil (Lorenzi, 2002), fato constatado no nosso levantamento em Lavras - MG, sendo a espécie que mais contribuiu na cobertura de copa na cidade.

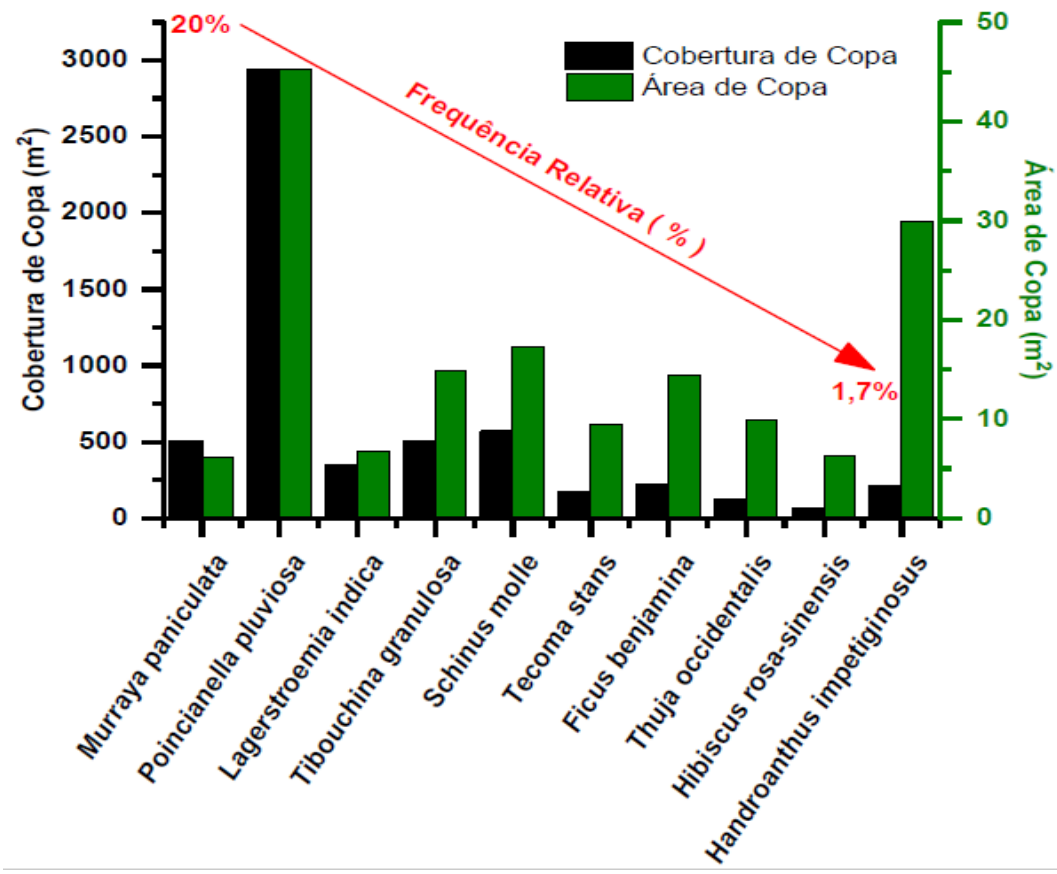

Figura 3. Cobertura de copa $\left(\mathrm{m}^{2}\right)$ das espécies que compõe a arborização viária dos bairros analisados em Lavras - MG

Figure 3. Canopy Coverage $\left(\mathrm{m}^{2}\right)$ of the species that make up the street trees neighborhoods analyzed in Lavras - MG 
Vale aqui ressaltar a importância do plantio de árvores de copas maiores nas cidades para o fornecimento de sombra, além de promoverem a interceptação da água das chuvas e consequentemente amenizando o escoamento superficial (SILVA et al., 2008), porém deve-se verificar cuidadosamente o seu local de plantio, a fim de evitar conflitos com os demais elementos urbanos (OLIVEIRA et al., 2015).

Ao comparar o número de árvores por quilômetro de via de Lavras - MG, com outras cidades brasileiras, constata-se a sua deficiência. Na cidade, o valor é de 9,57 Árvores.km ${ }^{-1}$, quando comparados com as cidades de Alta Floresta, Nova Monte Verde e Carlinda com 47,7, 52,3 e 56,0 Árvores.km ${ }^{-1}$, respectivamente (ALMEIDA; RODON NETO, 2010).

Na arborização viária de Lavras - MG está ocorrendo o fenômeno de "arbustificação", termo que exprime a tendência do aumento de plantio de espécies de hábito arbustivo nas cidades brasileiras, ao fato que $37,8 \%$ de seus indivíduos são de espécies de comportamento arbustivo, como é o caso das espécies Murraya paniculata (L.) Jack., Lagerstroemia indica L., Hibiscus rosa-sinensis L. e Brunfelsia uniflora (Pohl) D.Don. Isso ocorre, principalmente, devido às calçadas estreitas e falta de recuo entre as casas e a rua, o que leva à falta de espaço para o desenvolvimento de espécies de maior porte, já que 44\% dos indivíduos estão plantados em calçadas de até 1,5 $\mathrm{m}$ de largura. Em espécies de hábito arbustivo, a necessidade de podas é maior, para evitar que as suas ramificações ocupem o espaço de passagem do pedestre na calçada (OLIVEIRA et al., 2015).

A Figura 4 apresenta a origem das 43 espécies arbóreo-arbustivas catalogadas no inventário da arborização viária, observa-se que 56\% das espécies são exóticas da flora brasileira. O uso expressivo de espécies exóticas é generalizado nas cidades brasileiras (ALMEIDA; RONDON NETO, 2010) e esse fenômeno está relacionado à colonização europeia, com a introdução de espécies de outros países, ao desconhecimento das espécies potenciais da flora brasileira para a arborização e pela disponibilidade de espécies no mercado (LORENZI, 2002; SANTOS; ROCHA; BERGALLO, 2010).

A introdução de espécies exóticas deve ser observada com cuidado, visto que o plantio da espécie Murraya paniculata não é recomendável em regiões de citroculturas, pois ela é hospedeira do inseto vetor (Diaphorina citri) da Candidatus liberibacter, bactéria causadora da doença Huanglongbing-HLB (greening) em plantações de citrus (BOVÉ, 2006). E a espécie Tecoma stans possui características de espécie invasora, podendo afetar a produtividade de pastagens (LORENZI et al., 2003).

Foram identificadas 19 espécies que ocorrem naturalmente nos domínios fitogeográficos da Mata Atlântica e Cerrado, sendo quatro espécies exclusivas do primeiro, duas do segundo e treze espécies ocorrem concomitantemente nos dois domínios fitogeográficos. Em relação às espécies autóctones, ou seja, aquelas ocorrentes naturalmente 
em remanescentes vegetacionais do município de Lavras - MG, foram identificadas sete espécies.

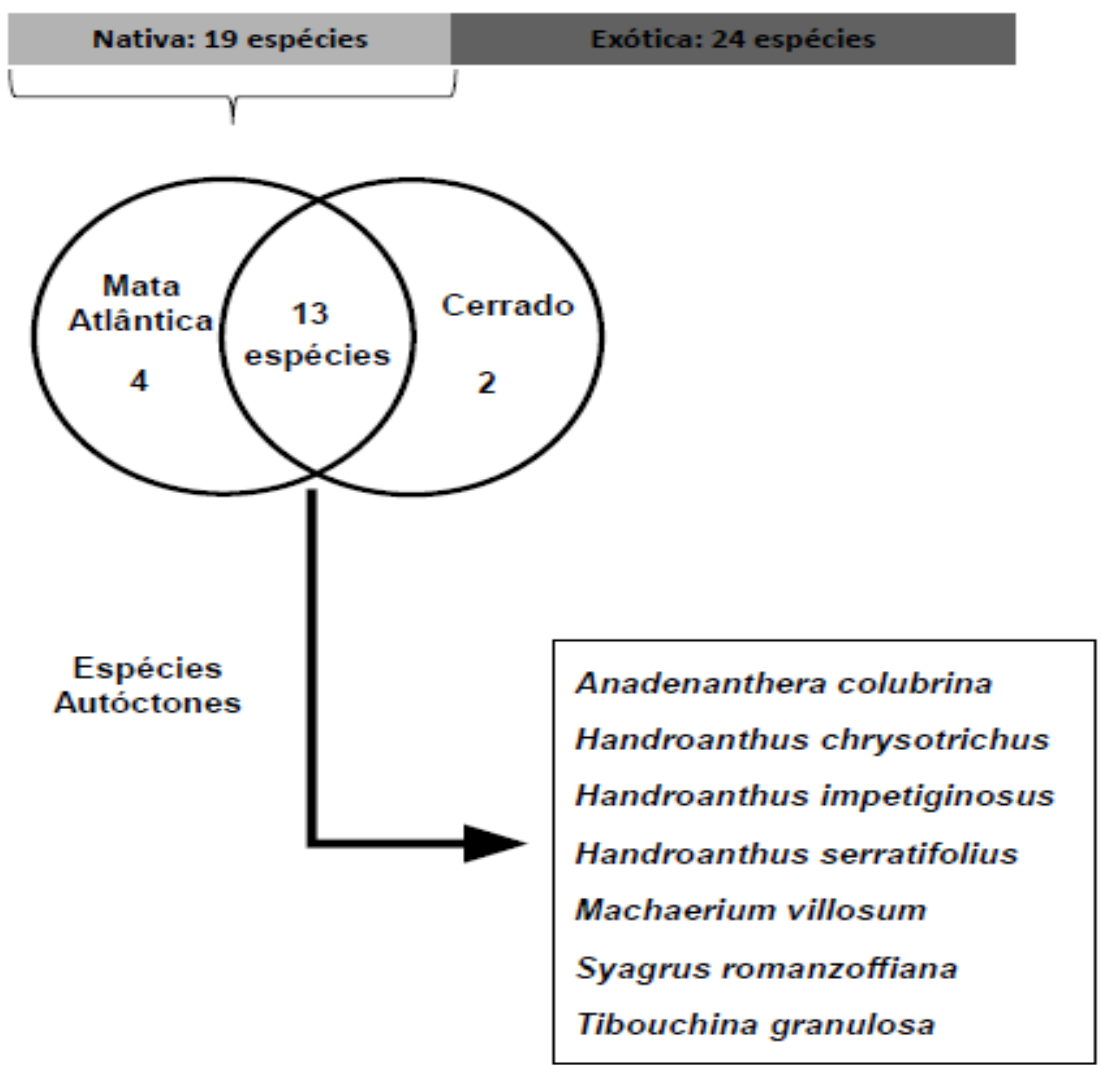

Figura 4. Origem das espécies arbórea-arbustivas da arborização viária de Lavras - MG Figure 4. Origin of tree and shrub species of street trees of Lavras - MG

O uso de espécies autóctones contribui com o paisagismo coerente com a região, permite a identificação da população com a vegetação local, além de serem mais adaptadas às condições locais e podem ser utilizadas como árvores matrizes para a obtenção de material propagativo (ALMAS; CONWAY, 2016; OSAKA; TAKENAKA; SILVA, 2016; CUPERTINO; EISELOHR, 2013; CASTRO; MORO; ROCHA, 2011).

Dentre as espécies autóctones estão três espécies do gênero Handroanthus (ipês), a utilização dessas espécies na arborização viária de Lavras - MG constitui uma forma de identificação e valor simbólico para a população local, pois a cidade de Lavras - MG possui o slogan "A cidade dos ipês e das escolas".

Diante do exposto é necessário a valoração de espécies autóctones para arborização do munícipio de Lavras-MG, visto apenas sete espécies foram contempladas. O desenvolvimento de pesquisas para determinar espécies autóctones potenciais é imprescindível para o planejamento de uma arborização viária de qualidade que garanta os seus benefícios sociais e ambientais. 


\section{CONCLUSÃO}

A arborização viária de Lavras-MG é composta por 43 espécies arbóreo-arbustivas, sendo que 19 espécies são nativas dos domínios fitogeográficos do Cerrado e/ou Mata Atlântica e dessas sete espécies são autóctones, com ocorrência natural em fragmentos florestais da região de Lavras - MG.

O uso de espécies autóctones deve ser ampliado na arborização viária e pesquisas para a determinação de espécies potenciais devem ser desenvolvidas.

Com relação a distribuição dos indivíduos entre as espécies, ela ocorre de maneira desuniforme, com frequência relativa acima do recomendável para as espécies Murraya paniculata, Poincianella pluviosa e Lagerstroemia indica.

Com o espaço reduzido das calçadas, o uso de espécies de hábito arbustivo vem se generalizando na malha viária, levando ao processo de "arbustificação".

\section{REFERÊNCIAS}

ALMAS, A.D.; CONWAY, T.M. The role of native species in urban forest planning and practice: A case study of Carolinian Canada. Urban Forest and Urban Greening, Munich, v. 17, p. 5462, 2016.

ALMEIDA, D.N.; RODON NETO, R.M. Análise da arborização urbana de três cidades da região norte do Estado de Mato Grosso. Acta Amazônica, Manaus, v.40, n.4, p. 647-656, 2010.

BOVÉ, J.M. Huanglongbing: a destructive, newly-emerging, century-old disease of citrus. Journal of Plant Pathology, Netherlands, v. 88, p. 7-37, 2006.

CASTRO, A. S. F.; MORO, M.F; ROCHA, F.C.L. et al. Plantas dos espaços livres da Reitoria da Universidade de Fortaleza (UNIFOR), Ceará, Brasil. Revista Brasileira de Biociências, Porto Alegre, v. 9, n. 1, p. 126-129, 2011.

CUPERTINO, M.A.; EISENLOHR, P.V. Análise florística comparativa da arborização urbana nos campi universitários do Brasil. Bioscience Journal, Uberlândia, v.29, n.3, p. 739-750, 2013.

DALANESI, P.E.; OLIVEIRA-FILHO, A.T.; FONTES, M.A.L. Flora e estrutura do componente arbóreo da floresta do Parque Ecológico Quedas do Rio Bonito, Lavras, MG, e correlações entre a distribuição das espécies e variáveis ambientais. Acta Botanica Brasilica, Belo horizonte, v.18, n.4, p. 737-757, 2004.

GÓMEZ-BAGGETHUN, E.; BARTON, D.N. Classifying and valuing ecosystem services for urban planning. Ecological Economics, Amsterdam, v. 86, p. 235-245, 2013.

INSTITUTO BRASILEIRO DE GEOGRAFIA E ESTATÍSTICA. Dados estatísticos das cidades mineiras. 2018. Disponível em: 
<http://www.ibge.gov.br/cidadesat/xtras/uf.php?coduf=31;search=minas-gerais $>$. Acesso em 10 nov. 2018.

LISTA DE ESPÉCIES DA FLORA DO BRASIL. Lista de espécies da flora do Brasil. 2012. Disponível em: http://floradobrasil.jbrj.gov.br/2012. Acesso em: 09 jan. 2016

LORENZI, H. Árvores brasileiras: manual de identificação e cultivo de plantas arbóreas nativas do Brasil: volume 1. 4. ed. Nova Odessa: Instituto Plantarum, 2002. 384 p.

LORENZI, H., et al. Árvores exóticas no Brasil: madeireiras, ornamentais e aromáticas. Nova Odessa: Instituto Plantarum, 2003. 384 p.

LUNDGREN, W.J.C.; SILVA, L.F.; ALMEIDA, A.Q. Influência das espécies exóticas árboreas urbanas na área de cobertura da cidade de Serra Talhada - PE. Revista da Sociedade Brasileira de Arborização Urbana, Piracicaba, v.8, n.3, p. 96-107, 2013.

MELO, B.M.; DIAS, D.P. Microclima e conforto térmico de remanescentes florestais urbanos no município de Jataí - GO. Revista da Sociedade Brasileira de Arborização Urbana, Curitiba, v.14, n.2, p. 1-15, 2019.

NOWAK, D. J.; GREENFIELD, E.J.; HOEHN, R.E.; LAPOINT, E. Carbon storage and sequestration by trees in urban and community areas of the United States. Environmental Pollution, Barking, v. 178, p. 229-236, 2013.

OLIVEIRA, A.F.; PEREIRA, J.A.A; PEREIRA, G.A.; COELHO, S.J.; NEVES, C.L.P.; REZENDE, S.W.; GARCIA, F.H.S. Modalidades de poda avaliadas na arborização viária sob rede elétrica no estado de Minas Gerais. Revista da Sociedade Brasileira de Arborização Urbana, Curitiba, v.10, n.2, p. 1-13, 2015.

OLIVEIRA-FILHO, A.T. TreeAtlan 2.0, Flora arbórea da América do Sul cisandina tropical e subtropical: Um banco de dados envolvendo biogeografia, diversidade e conservação. Universidade Federal de Minas Gerais, 2010. Disponível em: http: www.icb.ufmg.br/treeatlan/. Acesso em: 09 jan. 2013.

OSAKA, L.K.; TAKENAKA, E.M.M.; SILVA, P.A. Arborização urbana e a importância do planejamento ambiental através de políticas públicas. ANAP Brasil, Tupã, v. 9, n. 14, p. 1-8, 2016.

PEREIRA, I.M.; BERG, E.V.D.; PINTO, L.V.A.; HIGUCHI, P.; CARVALHO, D.A. Avaliação e Proposta de conectividade dos fragmentos remanescentes no campus da Universidade Federal de Lavras, Minas Gerais. Cerne, Lavras, v. 16, n. 3, p. 305-321, 2010.

RODRIGUES, T.D.; MALAFAIA, G.; QUEIROZ, S.E.E.; RODRIGUES, A.S.L. Percepção sobre arborização urbana de moradores em três áreas de Pires do Rio - Goiás. Revista de Estudos Ambientais, Blumenau, v.12, n. 2, p. 47-61, 2010.

ROLOFF, A.; KORN, S.; GILLNER, S. The climate-species-matrix to select tree species for urban habitats considering climate change. Urban Forest and Urban Greening, Munich, v. 8, p. 295-308, 2009.

SANTAMOUR, F. S. Trees for urban planting: diversity, uniformity and common sense. In: Conference of The Metropolitan Tree Improvement Alliance, 7., 1990, Lisle. Proceedings... Lisle: Metria, 1990. p. 57-65. 
SANTOS, A.R.; ROCHA, C.F.D.; BERGALLO, H.G. Native and exotic species in the urban landscape of the city of Rio de Janeiro, Brazil: density, richness, and arboreal deficit. Urban Ecosystems, Duluth, v.13, n.2, p. 209-222, 2010.

SILVA, L.F.; LIMA, A.M.L.P.; SILVA-FILHO, D.F.; COUTO, H.T.Z. Interceptação de chuva pelas copas das espécies de Caesalpinia pluviosa DC. (Sibipiruna) e Tipuana tipu O. Kuntze (Tipuana) em arborização urbana. Scientia Forestalis, Piracicaba, v.36, n.80, p. 307-315, 2008.

SOUZA, J.S.; ESPIRITO-SANTO, F.D.B; FONTES, M.A.L.; OLIVEIRA-FILHO, A.T.; BOTEZELLI, L. Análise das variações florísticas e estruturais da comunidade arbórea de um fragmento de floresta semidecídua às margens do rio Capivari, Lavras-MG. R. Árvore, Viçosa, v.27, n.2, p.185-206, 2003.

VILELA, E. A.; RAMALHO, M. A. P. Análise das temperaturas e precipitações pluviométricas de Lavras-MG, Ciência e Prática, Lavras, v. 3, n. 1, p. 71-79, 1979. 